\title{
Retraction Note: Agricultural super green image segmentation method based on Gaussian mixture model combined with Camshift
}

Jie Jiang ${ }^{1} \cdot$ Manru Gao ${ }^{2}$

Published online: 1 December 2021

C) Saudi Society for Geosciences 2021

Retraction Note: Arabian Journal of Geosciences (2021) 14: 925 https://doi.org/10.1007/s12517-021-07144-w

The Editor-in-Chief and the Publisher have retracted this article because the content of this article is nonsensical. The peer review process was not carried out in accordance with the Publisher's peer review policy. Author Manru Gao has not responded to correspondence regarding this retraction. The Publisher has not been able to obtain a current email address for author Jie Jiang.

The original article can be found online at https://doi.org/10.1007/ s12517-021-07144-w.

Manru Gao

befull31@163.com

1 School of Information Engineering, Xijing University, Xi'an 710123, China

2 Information Service Center, Wenzhou Business College, Wenzhou 325000, Zhejiang, China 